\title{
MENCARI WARISAN NABI DI INDONESIA DALAM PERSPEKTIF SEJARAH
}

\author{
Nurul Djazimah \\ Jurusan Perbandingan Agama Fakultas Ushuluddin dan Humaniora \\ IAIN Antasari Banjarmasin \\ Diterima tanggal 6 Pebruari 2015 / Disetujui tanggal 12 Maret 2015
}

\begin{abstract}
Indonesia is a country with the world's third largest population; about 90 percent of the population is Muslims. The history of the Islam in this country can be traced back to descendants of the prophet Mubammad. They played an important role in disseminating Islamic teachings in the archipelago. Until now descandants of the prophet still engage in Islamic preaching activities, understanding the legacy of the prophet from historical perspective is instructive, for that will help clarify the making of Muslim civilition in the archipelago. The prophet sent his companions to the area now known as Indonesia. His predecesors continued this tradition of sending companions in preaching missions nost notably in the time Utsman ibn Affan. The Islamic spiritual link with Indonesia was concrete: one preserved clothing of the prophet and a flag used in one of this own battles were given to the Sultan of Banten as gifts. Indeed, the community of Islamic believers shares the legacy of the prophet regardless of their orgins. Most prominently among them have been the Islamic preachers and Muslim warriors.
\end{abstract}

Kata kunci: prophet Legacy, spiritual link, the companions, sacred aura.

\section{Pendahuluan}

Jika setiap tahun umat Islam yang sedang menjalankan ibadah haji, maka di sekitar Ka'bah mereka akan menemukan artefak jejak kaki peninggalan Nabi Ibrahim as. Artefak itu ialah Maqam Ibrahim. ${ }^{1}$

Tetapi dengan judul mencari jejak Nabi di Indonesia bukanlah dengan maksud untuk mengadakan penelitian arkeologi. Karena itu kajian ini lebih ditekankan pada pencarian jalur penghubung antara ajaran Nabi Muhammad saw. dan peninggalan-peninggalannya dikaitkan dengan fakta sejarah yang ada di Indonesia.

Kajian ini diteliti mengingat adanya fakta sejarah bahwa agama Islam berada di Indonesia sudah sejak abad I H, bahkan sejak Nabi Muhammad saw. hidup dan diantara penyebar-penyebar Islam di Indonesia adalah bangsa Arab, ${ }^{2}$ Suku Quraisy keturunan Nabi.

Dalam hal ini M. Zainuddin berkata bahwa sebelum Nabi wafat telah dikirim utusan perintis ke negeri Cina. Setelah wafat berangkat lagi sebuah ekspedisi yang terdiri dari para muballigh Islam untuk berlayar ke negeri Cina dan singgah ke pelabuhan Aceh yaitu Lamuri.

\footnotetext{
${ }^{1}$ Ali Shariati, Wa Adzimu fi nafsi bi al Hajj, terj. Anas Mahyudin, (Bandung: Pustaka, 1983), h. 39.

${ }^{2}$ Abu Bakar Aceh, Sekitar Masuknya Islam ke Indonesia, (Semarang: PT. Ramadhani, 1971), h. 33.
} 
Adapun sumbernya adalah dibawa langsung dari Makkah al-Mukarramah yaitu oleh seorang Syech utusan dari Syarif Makkah al-Mukarramah ${ }^{3}$. Kemudian singgah di Malabar dan disitu telah ada seorang bekas raja yang menjadi sufi dan beliau adalah keturunan Abu Bakr as-Siddiq bernama Fakir Muhammad.

Pada masa pemerintahan Yazid bin Muawiyah yang terkenal sangat kejam dan sangat memusuhi kerabat Ali bin Thalib (peristiwa terbunuhnya Husain di Padang Karbela). Maka pada waktu itu banyak dari golongan Alawiyyin yang melarikan diri. Di antara mereka ada yang menjadi muballigh sambil berdagang dan membentuk perkampungan di Sumatera Barat, Umumnya mereka dari suku Quraisy di Mekah. Profesi sebagai pedagang memang sudah ada sejak zaman Nabi. ${ }^{4}$

Tentang kemahiran mereka berdagang telah diabadikan Tuhan dalam Alquran surah al-

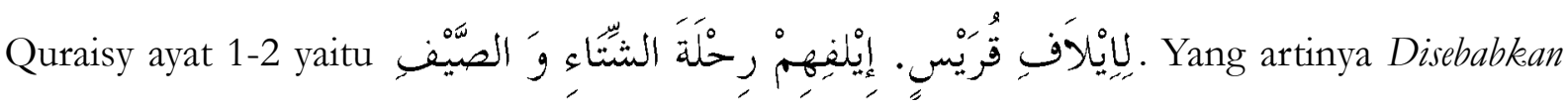
karena kebiasaan orang-orang Quraisy ialab mereka bepergian pada musim dingin dan musim panas (untuk urusan perdagangan).

Alasan lain munculnya permasalahan ini adalah proses islamisasi di Indonesia pada awal perkembangannya, bahwa kelompok penyebar Islam banyak diperankan oleh para Sayyid keturunan Nabi dan warisan Nabi disamping tidak bisa dipungkiri bahwa kelompok yang lainpun telah menghiasi khazanah sejarah perkembangan Islam di Indonesia.

Peranan Para Sayyid dalam Proses Islamisasi di Indonesia

Tentang siapa atau bangsa mana yang membawa Islam ke Indonesia. Pada umumnya para sejarawan berkesimpulan bahwa paling tidak ada tiga kelompok suku bangsa yang berjasa membawa dan mengembangkan agama Islam ke Indonesia. Mereka itu ialah para saudagar dari Arab, dari Gujarat (India) dan dari Persia. ${ }^{5}$ Peranan yang dilakukan orang-orang Islam di Persia ini sangat nyata walaupun bukan yang utama. ${ }^{6}$

Tetapi sejak awal mula masuknya Islam ke Indonesia telah terjadi hubungan rohani antara orang-orang Arab dengan orang Melayu secara langsung seperti sejarah tentang asal-usul masuknya agama Islam di Samudera Pasai. Bahwasanya seorang syarif Mekah telah mengutus seorang bernama Syech Ismail agar datang ke Samudera Pasai dan singgah di Malabar (Mu'tabar) serta menemui Sultan Muhammad untuk menyebarkan agama Islam di daerah tersebut. ${ }^{7}$ Selain itu seorang Syarif dari Mekah bernama Abdullah Araf juga telah datang ke Aceh untuk menyebarkan Islam di sana. ${ }^{8}$ Untuk memperkuat fakta sejarah tersebut Hamka telah mengemukakan teorinya bahwa menurut pengamatannya bahwa mazhab Syafi'i yang merupakan mazhab mayoritas bangsa Indonesia, mengindikasikan secara tepat bahwa Islam di Indonesia dibawa langsung dari daerah asalnya yaitu dari Mekah karena mazhab Syafi'i merupakan mazhab yang istimewa di Mekah. ${ }^{9}$

\footnotetext{
${ }^{3}$ Sayyid Muhammad bin Abd. Rahman bin Syihab, Hadirul Alamil Islam, jilid III, Cet. II, h. 162.

${ }^{4}$ Saifuddin Zuhri, Sejarah Kebangkitan Islam dan Perkembangannya di Indonesia, (Bandung: PT. al-Ma'arif, 1976), h. 215.

${ }^{5}$ Abu Bakar, Sekitar Masuknya Islam ke Indonesia, h. 33-34.

${ }^{6}$ Hamka, Sejarah Umat Isalm, Jilid IV, (Jakarta: Bulan Bintang, 1973), h. 41 (Lihat Philip K. Hitti, The Arab, terj. Hutagalung dan Sihombing, h. 107).

${ }^{7}$ Hamka, Sejarah Umat Isalm, h. 41.

${ }^{8}$ Hamka, Sejarah Umat Isalm, h. 41.

${ }^{9}$ Asnan Wahyudi dan Abu Khalid MA, Kisab Wali Sanga, Para Penyebar Islam di Tanah Jawa, (Surabaya: Karya Ilmu, t.th.), h. 11-12.
} 
Dalam catatan sejarah para wali penyebar agama Islam di tanah Jawa atau yang sering dikenal dengan wali Sembilan. Umumnya orang mengenal wali Sembilan adalah Syech Maulana Malik Ibrahim, Sunan Ampel, Sunan Bonang, Sunan Giri, Sunan Drajat, Sunan Kalijaga, Sunan Muria dan Sunan Gunung Jati.

Tetapi sebenarnya wali sembilan adalah sebuah dewan dakwah (muballigh) yang jumlahnya selalu sembilan orang. Sehingga jika salah satu diantara mereka wafat, maka segera diganti dengan yang lain, sehingga jumlahnya tetap sembilan orang. Tercatat para wali tersebut didirikan tahun 1404 M sebanyak 9 orang, tahun 1436 masuk tiga orang menggantikan yang wafat, pada tahun 1463 masuk empat orang lagi menggantikan yang wafat atau pergi.

Berikut ini adalah para wali Sembilan periode pertama (1) Maulana Malik Ibrahim wafat di Gresik, (2) Maulana Ishak beliau pindah ke Singapura dan wafat disana, (3) Maulana Ahmad Yumadil Kubra wafat di Mojokerto dimakamkan di Trowulan, (4) Maulana Muhammad alMaghribi wafat 1465 M makamnya di Yatinom Klaten, (5) Maulana Malik Israil wafat 1435 M makamnya di Gunung Santri Cilegon, (6) Maulana Muhammad Ali Akbar wafat 1435 M dimakamkan juga di Gunung Santri, (7) Maulana Hasanuddin wafat 1462 makamnya di Banten, (8) $\ldots \ldots \ldots \ldots \ldots$ (9) Syech Subakir wafat 1462 beliau pulang ke Persia. ${ }^{10}$

Maka Maulana Malik Ibrahim atau yang dikenal dengan Maulana Maghribi beliau berasal dari keluarga sayyid keturunan Nabi Muhammad saw. melalui jalur Ali Zainal Abidin cucu Ali bin Abi Thalib. ${ }^{11}$ Dari ibunya beliau adalah kemenakan putri Campa istri dari Raja Majapahit. Oleh Raja Majapahit ia diberi sebidang tanah, kemudian beliau mengabdikan diri untuk menyampaikan ajaran-ajaran Islam dan menjadi penguasa, di daerah tersebut bernama Ampel. Beliau wafat tahun 1467, peninggalan yang masih ada dan berdiri tegak adalah Masjid Ampel, ${ }^{12}$ yang setiap saat banyak dikunjungi orang untuk salat berjama'ah dan berziarah disana.

Silsilah Maulana Malik Ibrahim termaktub dalam kitab "Tarikhul Auliya” bahwa Maulana Malik Ibrahim adalah putra dari Maulana Jumadil Kubra bin Sayyid Zainal Husein bin Sayyid Zainal Kubra, bin Sayyid Zainul Abidin bin Sayyidina Husein binti Siti Fathimah binti Muhammad Rasulullah salallahu alihi wasallam.

Maulana Malik Ibrahim adalah seorang ulama dan muballigh Islam, beliau memiliki kepribadian yang sangat istimewa sehingga beliau diambil menantu oleh Raja Majapahit yang beragama Hindu. Dalam perjalanan hidupnya sebagai seorang muballigh beliau mendirikan pondok pesantren dan berhasil mendidik para santrinya untuk menjadi penerus muballigh Islam yang mahir dalam bidang agama sekaligus juga pemimpin masyarakat. ${ }^{13}$

Selain seorang muballigh sekaligus beliau juga ahli tata negara. ${ }^{14}$ Beliau juga dikenal dengan nama Maulana Maghribi karena beliau datang dari Maroko atau Afrika Utara, kuburannya berada di Gresik. ${ }^{15}$ 82.

\footnotetext{
${ }^{10}$ Ahmad Mansur Suryanegara, Menemukan Sejarab Wacana Pergerakan Islam di Indonesia, (Bandung: Mizan, 1996), h.

${ }^{11}$ Ahmad Mansur Suryanegara, Menemukan Sejarah Wacana Pergerakan Islam di Indonesia, h. 44.

${ }^{12}$ Lembaga Penelitian dan Studi DGI, Jerih dan Juang, (Jakarta: LPSDGI, 1979), h. 33.

${ }^{13}$ Saifudin Zuchri, Sejarah Kebangkitan Islam dan perkembangan di Indonesia, h. 267.

${ }^{14}$ Asnan Wahyudi dan Abu Khalid, Kitab Wali Sanga..., h. 17

${ }^{15}$ Saifudin Zuchri, Sejarah Kebangkitan Islam..., h. 262.
} 
Demikian pula Sunan Gunung Jati atau Syarif Hidayatullah atau lebih dikenal dengan Fathahillah. Nama kecilnya Syech Israil nama lainnya ialah Sayyid al-Kamil, ayahnya adalah bangsaw.an Quraisy yang keturunan Nabi, beliau dibesarkan di Samudera Pasai, kemudian menjadi menantu Raden Fatah raja Demak yang pertama. Beliau diberi daerah kekuasaan Banten dan Cirebon, selain seorang yang sangat alim sebagai keturunan Ali bin Abi Thalib beliau juga ahli dalam bidang politik seorang negarawan yang ahli dalam bidang siasat perang. Karena kegagahannya dalam berperang itu beliau dan laskarnya dapat mengusir bangsa Portugis yang ingin menjajah Indonesia dari Batavia. Atas kemenangannya itu beliau diberi gelar Fathahillah atau pembuka pintu kemenangan oleh Syarif dari Mekah. ${ }^{16}$

Syech Ja'far Sidiq atau yang lebih dikenal dengan Sunan Kudus, beliau juga termasuk salah satu dari wali sembilan periode ketiga. Lokasi dakwahnya berada di Jawa Tengah di kota Kudus. Nama ini diambil sebagai kenang-kenangan karena beliau dari Baitul Maqdis Palestina. Beliau seorang syech keturunan Ali bin Abi Thalib dari jalur Syech Ja'far Sodiq yaitu imam ke enam dalam kepercayaan Syiah. Dalam berdakwah beliau berusaha memperkuat ajaran Islam dan mengikis habis pengaruh ajaran Hindu. ${ }^{17}$ Berbeda dengan Sunan Kalijaga yang dalam berdakwah menggunakan metode dengan pendekatan budaya seperti melalui pagelaran wayang dalam upacara pensyahadatan masal, dan orkestra tradisional yang dikenal dengan gending Sunan Kalijaga.

Hal ini disebabkan karena Islam datang di Nusantara waktu itu, bangsa Indonesia tidak dalam keadaan vakum kultural, tetapi telah memiliki budaya asli yang berakar pada kebudayaannya sendiri. Meskipun kebudayaannya tidak setinggi peradaban Cina, Byzantium maupun Persia, tetapi kebudayaan Jawa sudah cukup tinggi yang kemudian mendapat pengaruh oleh kebudayaan Hindu dan Budha. ${ }^{18}$

Namun demikian para muballigh Islam yang datang ini semuanya mengajarkan ajaran agama Islam dan gaya hidup yang secara kualitatif lebih maju dari peradaban yang ada. Bukan saja dalam perenungan teologi monotheisme saja, tetapi di bidang kehidupan masyarakat yang tidak mengenal pembagian kasta dapat merubah gaya hidup feodal pedalaman yang berkasta dan berjiwa agraris statis menjadi berjiwa wiraswasta yang dinamis dan merupakan suatu kekuatan pembebasan social (a social liberating forse). ${ }^{19}$

Pengaruh Islam Arab atau Mekah di Indoensia ini oleh Snouck Hurgronje diakui, bahkan pengaruhnya lebih kuat daripada di Turki, Hindustan dan Bukhara sendiri. ${ }^{20}$

Hal ini lebih diperkuat lagi oleh Rowlandson ia berkata: "Orang Arab Islam itu sejak pertama sekali telah menetap di tepi pantai Malabar pada akhir abad ke-7 M". Pendapat ini lebih diperkuat lagi oleh Sturrock dan Francis Day mereka berkata bahwa pedagang Persia dan Arab telah menetap sejak dari abad ke-7 dan kawin dengan perempuan-perempuan pribumi kemudian membentuk koloni-koloni di Pantai Malabar. ${ }^{21}$

\footnotetext{
${ }^{16}$ Hamka, Sejarah Umat Islam, h. 141.

${ }^{17}$ Hamka, Sejarah Umat Islam, h. 22.

${ }^{18}$ Ruslan Abdul Gani, Sejarah Perkembangan Islam di Indonesia, (Jakarta: Pustaka Antar Kota, 1983), h. 20.

${ }^{19}$ Ruslan Abdul Gani, Sejarah Perkembangan Islam di Indonesia, h. 22.

${ }^{20}$ Snouck Hurgronje, Ensyclopidie Van Den Indie, h. 576.

${ }^{21}$ Francis Day, The Land of Parumls, h. 365.
} 
Raden Rahmat atau yang lebih dikenal dengan Sunan Ampel, beliau adalah putera dari Syech Maulana Malik Ibrahim. Sama dengan ayahandanya berarti beliau juga keturunan Nabi dan Fathimah az Zahra dari jalur Zainal Abidin.

Setelah ayahnya wafat, maka pondok pesantren yang didirikan oleh ayahnya diserahkan kepada Raden Rahmat dan sebagaimana Maulana Malik Ibrahim Raden Rahmat pun memiliki jiwa kepemimpinan untuk membentuk masyarakat yang gemah ripabtata tentrem (subur makmur penuh dengan kedamaian) dan jujur.

Profil dakwah beliau lebih menitik beratkan untuk mendidik orang agar berfikir secara bijaksana dengan argumentasi yang masuk akal. Itulah kiatnya sehingga dalam waktu relatif singkat telah memiliki pengaruh yang luas ditengah masyarakat dan namanya harum sebagai pelita ketertiban dan keamanan. Ruang gerak beliau di sekitar Ampel Surabaya. ${ }^{22}$

Peninggalan dan Ajaran Nabi dalam kaitannya dengan Fakta sejarah di Indonesia.

\section{a. Peninggalan Nabi}

Pada waktu Nabi Muhammad saw. masih hidup beliau sering mengutus sahabat-sahabat beliau ke berbagai Negara antara lain: Mesir, Yaman, Romawi dan Persia. Di antara sahabat Nabi yang dikirim ke berbagai negara waktu itu ialah Saad ibn Abil Waqas. Beliau adalah panglima perang dalam menaklukkan Persia. ${ }^{23}$

Kemudian setelah itu beliau dikirim oleh Nabi untuk menyampaikan dakwahnya ke negeri Cina, dan sampai wafat beliau tidak pernah kembali ke negeri Arab. Bukti kebenaran sejarah tersebut adalah kuburan Saad ibn Abi Waqas sampai sekarang tetap berada di China yaitu di kota Canton. Makam tersebut senatiasa diziarahi dan dihormati orang-orang Muslim di sana. ${ }^{24}$

Untuk memperkuat fakta sejarah tersebut kita perlu ingat sebuah hadis Nabi:

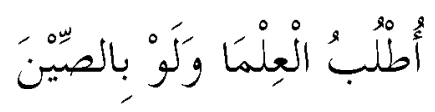

"Tuntutlah ilmu walaupun sampai ke Negeri China (al-Hadits)".

Di Indonesia kita lebih beruntung mendapatkan jejak Nabi yaitu melalui keturunan Nabi serta zuriat yang sangat berjasa dalam proses islamisasi ke berbagai wilayah terutama di pulau Jawa sebagaimana bukti sejarah tentang kehadiran para wali Allah terutama Wali Sanga dan bangsa Indonesia cukup atau lebih beruntung karena seorang Sultan (Abd Qadir) dari Banten Jawa Barat yang berkuasa pada tahun 1625-1651 mengirimkan misi diplomatik ke tanah suci Mekah. Dan dari hasil misi tersebut penguasa Mekah memberikan gelar Sultan dan juga memberikan hadiah yang diyakini berupa "bendera dan pakaian Nabi". Semua pemberian Syarif Haramain tersebut setiap bulan Maulid diarak pada prosesi peringatan maulid Nabi Muhammad saw. di Banten. ${ }^{25}$

${ }^{22}$ Saifudin Zuchri, Sejarah Kebangkitan Islam..., h. 268-270.

${ }^{23}$ A. Syalabi, Sejarah dan Kebudayaan Islam, terj. Muchtar Yahya, Jayamurni, 1973, h. 115.

${ }^{24}$ Syamsu Dhuha, Penyebaran dan Perkembangan Islam, Katholik, dan Kristen Protestan di Indonesia, Surabaya: t.th., h. 21.

${ }^{25}$ Azyumardi Azra, Jaringan Ulama Timur Tengah dan Kepulauan Nusantara Abad XV II dan XV III, (Bandung: Mizan, 1995), h. 55-56. 
Sewaktu beliau masih hidup juga mengutus seorang sahabat beliau seorang mufassir (ahli tafsir) dan muhaddisin (perawi hadis) zaman Nabi bernama Ibnu Mas'ud (606-699 M). Menurut ahli sejarah Ibnu Mas'ud inilah yang pertama kali dikirim oleh Rasulullah saw. ke nusantara.

G.E. Gerimi dalam bukunya yang berjudul: Futhe Yudia and Yudo ilalay Archipelago menyatakan bahwa Ibnu Mas'ud dikirim ke Indonesia (Nusantara) sekitar tahun $625 \mathrm{M}$, bersama kabilahnya yaitu kabilah Thoyt, dan bermukim di Sumatera yaitu Aceh. ${ }^{26}$

Gelar-gelar Sultan di Indonesia pada umumnya adalah pemberian penguasa Mekah sebagai tanda penghargaan kepada para penguasa-penguasa muslim, terutama jika penguasa tersebut berjasa dalam menegakkan dan menyebarkan ajaran Islam.

Disamping adanya hubungan diplomatik bangsa Indonesia dengan penguasa Haramain.Masih ada lagi hubungan yang bersifat keagamaan. Dinyatakan bahwa sultan Aceh mendapat kehormatan besar dari Mekah dan menerima hadiah stempel mas Bayt al Haram. Stempel mas tersebut diberikan sebagai tanda penghormatan, karena Sultan Aceh tersebut seorang Darwisy Sufi yang baik dan beriman. ${ }^{27}$

Surat-surat, hadiah dan gelar-gelar yang diberikan oleh pemerintah Mekah sejak abad ke12 sampai abad ke-17 dipandang oleh penguasa muslim Nusantara umumnya memiliki aura kesucian yang bersumber dari tempat yang paling suci dalam tradisi Islam. ${ }^{28}$

\section{b. Pemahaman terhadap ajaran Nabi (kekuasaan)}

Dalam hal pemahaman terhadap kekuasaan pada umumnya Raja Melayu dan Sulthan menganut konsepsi bahwa Rasul dan raja adalah dua permata pada satu cincin.

Dalam kitab Undang-Undang Pahang bahkan dalam al Salatin lebih diperinci lagi bahwa Nabi dan Rasul mempunyai fungsi nubuwwah yakni fungsi keagamaan yang merupakan pohon dari seluruh kebesaran, kemuliaan dan kebenaran, dan ini adalah kawasan Ilabiyah. Di sisi lain Rasul juga berfungsi sebagai bukumah yaitu fungsi politik yang akan memelihara seluruh hamba Allah dari berbagai bentuk kejahatan menuntun mereka ke jalan kebaikan ini adalah ranah kerajaan, kekuasaan dan tahta. ${ }^{29}$

Lebih jauh lagi pada umumnya gelar Zillullah fil alam digunakan oleh sulthan-sulthan Malaka Samudera Pasai, sebagai penguasa Aceh dan Raja Melayu Pattani juga memiliki gelar-gelar tersebut bahkan ditulis pada mata uang yang beredar di wilayah Nusantara. ${ }^{30}$

Raja-raja Mataram pada umumnya bergelar Sultan. Dimulai dari Sultan agung yang mendapat pengakuan dari penguasa Mekah, disamping gelar raja Mataram juga menambahkan gelar Khalifatullah dan Sayyidina Panatagama. ${ }^{31}$ Lengkapnya ialah Prabu Mangkurat Senopati Ingaloga Ngabdur Rachman Sayyidina Panatagama Khalifatullah saw.. artinya kurang lebih: seorang raja yang menguasai dunia seorang hamba Tuhan (Yang Maha Penyayang) Pangeran yang menata agama pengganti Allah dan rasul-Nya.

\footnotetext{
${ }^{26}$ Kanhul Qalam.Com/2012/07/18/ Misteri Pemeluk Islam yang Pertama di Nusantara, tanggal 29 April 2014.

${ }^{27}$ Azyumardi Azra, Jaringan Ulama Timur Tengah..., h. 55

${ }^{28}$ Azyumardi Azra, Jaringan Ulama Timur Tengah...,h. 57.

${ }^{29}$ Husain Khalid, Taj al Salton, Dewan Bahasa dan Pustaka, Kuala Lumpur, 1966, h. 48-50.

${ }^{30}$ Nuruddin al-Raniri, Bustan al Salatin, Bab II, Kuala Lumpur, T. Iskandar, 1966, h. 36-44.

${ }^{31}$ Hamka,Sejarah Umat Islam, h. 81.
} 
Dalam kitab Jawi Klasik banyak meriwayatkan kisah yang bersumber dari tradisi Islam dan lokal.Tradisi politik tersebut mengandung pesan moral yang harus diikuti atau sebaliknya dihindari oleh penguasa dan rakyat.

Di antara kitab-kitab klasik yang mengandung pesan-pesan moral politik tersebut antara lain Hikayat Raja-Raja Pasai, Sulalat al Salatin, Taj Solatin. ${ }^{32}$

Dalam kitab Undang-Undang Malaka yang disusun tahun 1450, Sultan Muzaffar Syah menyebut para sultan Malaka sebagai khilafat al Mukmin, Zill Allah fil al ardh (Khalifah kaum muslimin bayang-bayang Allah di Muka bumi).

Indikasi politik terutama dalam hal kesultanan pada umumnya di Nusantara ini mengindikasikan keinginan politik dan keagamaan Islam yang ingin diakui sebagai bagian integral Dar al Islam. Karena itulah maka nama resmi kesultanan Samudera Pasai sebagai Samudra Dar al Islam, sedang Nur al Din al Raniri dalam Bustanul al Salatin menyebut kesultanan Aceh sebagai Dar al Islam. ${ }^{33}$

Manifestasi dari Dar al Islam sebagaimana ditulis dalam Taj al Salatin bahwa: Jika ucapan dan perbuatan Raja telah berpaling dari Allah dan menyimpang dari hukum Allah dan menolak syari'ah, maka rakyat wajib memperlakukan sebagai musuh Allah juga musuh-musuh mereka sendiri. ${ }^{34}$

Sebaliknya sebagaimana ajaran Sunni pada umumnya maka kepatuhan kepada raja atau penguasa adalah mutlak bagi rakyatnya, selama raja atau sultan tersebut menjalankan roda pemerintahan sebagaimana ajaran Allah dan Rasulnya.

\section{c. Bendera Merah Putih dan angka 17}

Proklamasi Indonesia pada tanggal 17 Agustus 1945 bertepatan dengan 9 Ramadhan 1364 hari Jum'at Legi. Proklamasi pada waktu itu dibacakan pada saat umat Islam di Indonesia yang beragama Islam sedang menjalankan ibadah puasa.Karena itu proklamasi juga dikumandangkan melalui mimbar-mimbar khotbah Jum'at.

Dipilihnya tanggal 17 Agustus juga bukan hal yang kebetulan saja, tetapi sudah direncanakan sejak tanggal 10 Agustus 1945 di Saigon. Terpilihnya tanggal 17 mengingatkan kewajiban umat Islam shalat sehari semalam 17 raka'at dan juga al Qur'an al Karim diturunkan ke dunia kepada Rasulullah saw. juga pada tanggal 17 Ramadhan. ${ }^{35}$

Fakta sejarah tersebut menajdi kabur dan kehilangan makna hal ini disebabkan karena setiap kali memperingati hari kemerdekaan RI tanggal 17 Agustus tidak pernah menyebutnyebut bulan Ramadhan dan makna yang tersirat pada angka 17 tersebut yang memang direncanakan secara seksama oleh pendiri-pendiri kemerdekaan yang mayoritas pada waktu itu adalah para ulama dan umat Islam.

Sebuah keajaiban sejarah, suatu momentum yang menakjubkan bagi bangsa Indonesia. Karena ia berani tampil sebagai bangsa yang merdeka. Sementara sekutu (Amerika, Inggris, Prancis dan Rusia) baru saja menandatangani perjanjian di Postdam.Yang menyetujui Indonesia

${ }^{32}$ Azyumardi Azra, Renaissans Islam Asia Tenggara, Sejarab Wacana dan Kekuasaan, (Bandung: Remaja Rosada, 1999), h. 90 .

${ }^{33}$ Azyumardi Azra, Jaringan Ulama Timur Tengah..., h. 92.

${ }^{34}$ Husein Khalid, Taj. Al Saton, h. 29-30

${ }^{35}$ Ahmad Mansur Suryanegara, Menemukan Sejarab Wacana Pergerakan Islam di Indonesia, (Bandung: Mizan, 1996), h. 288. 
sebagai wilayah jajahan Belanda.Demikian juga sekutu baru saja mendemonstrasikan keberhasilannya menghancurleburkan Hiroshima dan Nagasaki dengan bom atom tanggal 6 dan 9 Agustus 1945.

Oleh karena itu tepat sekali Proklamasi 17 Agustus yang terjadi di hari suci (Jum'at) dan bulan suci Ramadhan, hari ke-9 yang jatuh pada puluhan pertama Ramadhan mengandung nilai berkat dan rahmat dari Allah swt..

Berkat dan rahmat Allah swt.. ini secara tepat sekali telah dirumuskan oleh pendiri-pendiri kemerdekaan RI yang tertuang dalam Mukaddimah UUD 1945 berbunyi: "Atas Berkat dan Rahmat Allah yang Maha Kuasa da dengan didorongkan oleh keinginan luhur, supaya berkehidupan kebangsaan yang bebas, maka Rakyat Indonesia menyatakan dengan ini kemerdekaannya". ${ }^{36}$

Dalam UUD 1945 bab XV pasal 35 menyatakan bahwa bendera kebangsaan Indonesia adalah Merah Putih. Pemilihan warna merah putih inipun menurut sejarah adalah karena keinginan para pendiri kemerdekaan untuk senantiasa mengikuti sunnah Rasul saw. serta warna merah putih sudah menjadi lambang pada kesultanan dan kerajaan-kerajaan sebelum Islam.

Dalam Kitab al Fitan jilid X dinyatakan bahwa: Hamisy Qastalani, Imam Muslim berkata Zuhair bin Harb bercerita kepadaku demikian Ishak bin Ibrahim, Muhammad bin Mutsanna dan Ibnu Basyar Ishak bercerita kepada kami orang-orang lain berkata: Muadz bin Hisyam bercerita kepada kami, ayah saya bercerita kepadaku dari Qatadah dari Abu Tsa'labah dari Abu Asma al Rahabi dari Tsauban, Nabi saw. bersabda: "Sesungguhnya Allah memperlihatkan kepadaku bumi, timur dan baratnya. Allah melimpahkan dua perbendaharaan kepadaku yaitu Merah dan Putih. ${ }^{37}$

Dalam kehidupan sehari-hari warna merah putih merupakan busana Nabi Muhammad saw. yaitu surban dan jubbah warna putih di lehernya senantiasa terlilit selendang warna merah, warna merah putih tersebut senantiasa beliau pakai sampai akhir wafatnya. ${ }^{38}$

Penutup

Mencari warisan Nabi di Indonesia dalam perspektif sejarah dimaksudkan yaitu pencarian jalur penghubung antara ajaran Nabi Muhammad saw.. dengan peninggalan-peninggalannya dikaitkan dengan fakta-fakta sejarah Islam di Indonesia. Hal ini disebabkan karena proses Islamisasi di Indonesia sudah ada sejak abad pertama Hijriyah, yaitu sejak Nabi masih hidup. Diantara pembawanya adalah bangsa Arab suku Quraisy keturunan Nabi Muhammad saw. (para sayyid).

Diantara peninggalan-peninggalan yang diwariskan kepada umat Islam salah satunya ialah baju dan bendera Nabi Muhammad saw. yang ditinggalkan untuk umat Islam di Indonesia yaitu di kerajaan Banten, serta stempel mas Bayt al Haram yang diberikan kepada sultan di Aceh yang dipandang oleh penguasa muslim di Indonesia, memiliki aura kesucian yang datang di tempat yang paling suci dalam tradisi Islam. Diantara pemahaman terhadap ajaran Nabi

${ }^{36}$ Tim Pembinaan Penataran dan Bahan Penataran Pegawai RI, Undang-Undang Dasar, Pedoman Penghayatan dan Pengamalan Pancasila, Garis-garis Besar Haluan Negara, h. 1.

${ }^{37}$ Lembaga Al-Qur'an dan Hadits Majelis Tinggi Urusan Agama Islam Kekementerian Waqaf Mesir, Kelengkapan Hadis Qudsy, alih bahasa M. Zuchri, Semarang, Toha Putra, 1982, h. 368-372.

${ }^{38}$ Ahmad Mansur Suryanegara, Menemukan Sejarah Wacana Pergerakan Islam di Indonesia, h. 290. 
dalam konteks sejarah yaitu bahwa rasul mempunyai dua fungsi, yaitu fungsi nubuwwah dan hukumah. Demikian juga para sulthan dan raja-raja Islam di Indonesia memiliki dua fungsi tersebut.

Proklamasi RI tanggal 17 Agustus 1945 berlatar belakang nilai spiritual religious Islami yaitu bahwa pemilihan angka 17 sengaja untuk agar umat Islam senantiasa terkait dengan kewajiban shalat 17 rakaat sehari semalam dan tanggal 17 Ramadhan diturunkannya Alquran sebagai petunjuk umat Islam kepada Nabi Muhammad saw.. Bendera Merah Putih bendera kebangsaan RI adalah suatu keinginan moral untuk mengikuti sunnah Rasul yang merupakan perbendaharaan Nabi. Yakni warna merah pada surban Nabi dan baju putih ini adalah warna kesukaan Nabi yang dipakai sampai beliau wafat.

\section{DAFTAR PUSTAKA}

Aceh, Abu Bakar. (1971). Sekitar Masuknya Islam ke Indonesia, Semarang: PT. Ramadhani. al-Raniri, Nuruddin. (1966). Bustan al Salatin, Bab II, Kuala Lumpur: T. Iskandar. Azra, Azyumardi. (1995) Jaringan Ulama Timur Tengah dan Kepulauan Nusantara Abad XVII dan XVIII, Bandung: Mizan.

. (1999). Renaissans Islam Asia Tenggara, Sejarah Wacana dan Kekuasaan, Bandung: Remaja Rosada.

bin Syihab, Sayyid Muhammad bin Abd. Rahman. Hadirul Alamil Islam, jilid III, Cet. II.

Dhuha, Syamsu. (t.th.) Penyebaran dan Perkembangan Islam, Katholik, dan Kristen Protestan di Indonesia, Surabaya.

Gani, Ruslan Abdul. (1983). Sejarab Perkembangan Islam di Indonesia, Jakarta: Pustaka Antar Kota. Hamka. (1973). Sejarah Umat Isalm, Jilid IV, Jakarta: Bulan Bintang.

Hurgronje, Snouck Ensyclopidie Van Den Indie.

Khalid, Husain. (1966). Taj al Salton, Dewan Bahasa dan Pustaka: Kuala Lumpur.

Lembaga Al-Qur'an dan Hadits Majelis Tinggi Urusan Agama Islam Kekementerian Waqaf Mesir, (1982). Kelengkapan Hadis Qudsy, alih bahasa M. Zuchri, Semarang: Toha Putra. Lembaga Penelitian dan Studi DGI. (1979) Jerih dan Juang, Jakarta: LPSDGI.

Musthafa, Bisyri. (1952). Aulia, Kudus: Menara Kudus.

Shariati, Ali. (1983). Wa Adzimu fi nafsi bi al Hajj, terj. Anas Mahyudin, Bandung: Pustaka.

Suryanegara, Ahmad Mansur. (1996). Menemukan Sejarah Wacana Pergerakan Islam di Indonesia, Bandung: Mizan.

Syalabi, A. (1973). Sejarah dan Kebudayaan Islam, terj. Muchtar Yahya. Jayamurni.

Tiam Pembinaan Penataran dan Bahan Penataran Pegawai RI, Undang-Undang Dasar, Pedoman Penghayatan dan Pengamalan Pancasila, Garis-garis Besar Haluan Negara.

Wahyudi, Asnan dan Abu Khalid. (t.th.). Kisah Wali Sanga, Para Penyebar Islam di Tanah Jawa, Surabaya: Karya Ilmu.

Zuhri, Saifuddin. (1976). Sejarah Kebangkitan Islam dan Perkembangannya di Indonesia, Bandung: PT. al-Ma'arif. 